\title{
Article \\ Grounding Fault Model of Low Voltage Direct Current Supply and Utilization System for Analyzing the System Grounding Fault Characteristics
}

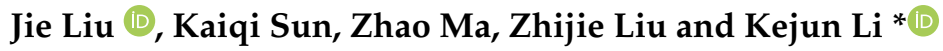 \\ School of Electrical Engineering, Shandong University, Jinan 250061, China; Jerry_Ljie@mail.sdu.edu.cn (J.L.); \\ skq@sdu.edu.cn (K.S.); zhao.ma@sdu.edu.cn (Z.M.); liuzj@sdu.edu.cn (Z.L.) \\ * Correspondence: lkjun@sdu.edu.cn; Tel.: +86-531-8169-6309
}

Citation: Liu, J.; Sun, K.; Ma, Z.; Liu, Z.; Li, K. Grounding Fault Model of Low Voltage Direct Current Supply and Utilization System for Analyzing the System Grounding Fault Characteristics. Symmetry 2021, 13, 1795. https://doi.org/10.3390/ sym13101795

Academic Editor: Christos Volos

Received: 6 September 2021

Accepted: 23 September 2021

Published: 26 September 2021

Publisher's Note: MDPI stays neutral with regard to jurisdictional claims in published maps and institutional affiliations.

Copyright: (C) 2021 by the authors. Licensee MDPI, Basel, Switzerland. This article is an open access article distributed under the terms and conditions of the Creative Commons Attribution (CC BY) license (https:/ / creativecommons.org/licenses/by/ $4.0 /)$.

\begin{abstract}
Grounding fault analysis is of vital importance for low voltage direct current (LVDC) supply and utilization systems. However, the existing DC grounding fault model is inappropriate for LVDC supply and utilization system. In order to provide an appropriate assessment model for the DC grounding fault impact on the LVDC supply and utilization system, an LVDC supply and utilization system grounding fault model is proposed in this paper. Firstly, the model is derived by utilizing capacitor current and voltage as the system state variable, which considers the impact of the converter switch state on the topology of the fault circuit. The variation of system state parameters under various fault conditions can be easily obtained by inputting system state data in normal conditions as the initial value. Then, a model solution algorithm for the proposed model is utilized to calculated the maximum fault current, the system maximum fault current with different grounding resistance is simple to acquired based on the solution algorithm. The calculation results demonstrate that grounding resistance and structure of LVDC supply and utilization system have remarkable impacts on the transient current. The effectiveness of the proposed model is verified in PSCAD/EMTDC. The simulation results indicate that the proposed method is appropriate for the system fault analysis under various fault conditions with different grounding resistance and the proposed model can offer theoretical guidance for system fault protection.
\end{abstract}

Keywords: low voltage direct current (LVDC) supply and utilization system; grounding fault; transient current; grounding resistance

\section{Introduction}

Due to the over-depleting of fossil fuels and the stress of climate change, the energy need is shifting from conventional fossil fuels to renewable energies [1-3]. Most renewable energies such as photovoltaic (PV) use the direct current connection, which is totally different from the conventional energy plant [4-6]. On the other hand, the loads and other devices in the supply and utilization system are changing to DC operation with electronic technology development. Thus, the future structure of the power distribution system will be changed to a network-style structure involving a large number of renewable energies and DC loads $[7,8]$, which could generate power for their own needs and will have a power trading function to address periods of over-/under-capacity [9]. The low voltage direct current (LVDC) supply and utilization system will play a significant role in the new structure of the power distribution system.

LVDC supply and utilization system is a DC ecological power supply and utilization system consisting of renewable energies, energy storage systems, and DC loads. The LVDC supply and utilization system could provide efficient and sustainable power for LVDC consumers, which follows the developing path of the future power network. Compared with the traditional AC power system, the LVDC supply and utilization system has simpler control for renewable energy without considering synchronization and reactive power. 
LVDC supply and utilization system can be utilized for power access via the employment of locally DC power generation without any conventional sources, achieving greater energy efficiency to avoid conduction loss during the process of conversion from AC to DC. LVDC supply and utilization system can also be used as an alternate energy-efficient system for the electrical distribution network.

There are many DC demonstration projects that have studied the LVDC supply and utilization system [10]. However, some of the relevant important technology, such as grounding type and grounding fault analysis, are still a challenge and need to be investigated further. LVDC supply and utilization system mainly provide service for the power consumer who generally has no professional electrical skill or knowledge [11-13]. Therefore, safety is one of the most significant considerations for grounding type selection. Meanwhile, the grounding type has a non-negligible impact on the system transient current and voltage in the fault condition, and the protection schemes against electric shock are mainly based on the grounding type $[14,15]$. Some grounding type advice has been suggested for the LVDC supply and utilization system for the purpose of personal and LVDC equipment safety $[16,17]$. For example, only one protective earthing system in the installations is recommended. The galvanic separation is required for using a different earthing system downstream an inverter or converter. Different grounding types of LVDC supply and utilization systems, such as solid grounding, resistive grounding, and impedance-type grounding, have a remarkable impact on system safety $[16,18]$. It has been proved that each grounding type has specific advantages and disadvantages, and an appropriate grounding type can be utilized for different purposes based on these.

Existing research on system grounding types is mainly focused on the grounding fault analysis based on different grounding types [19-22]. In [19], the fault models of a low voltage power system are developed for the system grounding fault analysis, and the variation of fault current with grounding resistance has been acquired based on the system fault analysis. A fault-calculation method for a grid-connected PV station is proposed in [20] based on the fault characteristics analysis of the system. In [21], a DC link adjustable resistive type fault current limiter based on fault analysis of converter is proposed to improve fault ride-through capability. Grounding the midpoint of the converters through resistance was recommended in this literature. In [22], A phase-to-ground fault analysis based on the symmetrical components method is utilized to describe the fault current phasor diagram, which will help in the application of ground fault protection. Additionally, many kinds of research have been assigned to the influence of fault transient current on the neutral point clamped converter [23]. These studies are mainly related to AC system fault analysis. The DC system fault analysis has been addressed only in a few references [24,25]. The operation of a grounded LVDC system in different situations has been studied in [16]. In [24], a fault current model with only high-frequency components of the fault HVDC network and a non-unit DC fault detection method utilizing the transient average value was proposed. The fault component of the AC part is ignored in this literature, which is non-negligible in the fault current analysis of the LVDC system. A pole-to-ground fault analysis method based on common and differential mode was presented in [25], which is suitable to HVDC grid topologies, and provides a new perspective to understand the fault mechanism. However, this model is not appropriate for the neutral point clamped converter system, which is popular in the LVDC supply and utilization system due to its advantages, such as low voltage stresses and easy utilization for producing high voltages.

In this paper, a grounding fault model is proposed to analyze the system fault characteristics under various fault conditions. The development procedures of the method include the following procedures:

(1) At first, the system steady-state model in normal conditions is derived based on the Kirchhoff's voltage and current theorem and the switching state vector.

(2) Then, the DC-link capacitor current and voltage are utilized as the system state variable in fault condition to further derive the model. 
(3) To the end, a novel solution algorithm based on the Fourth-order Runge-Kutta method and Monte Carlo method is employed in this paper to solve this model.

The fault signature under various fault conditions with different switching states of the AC/DC converter is obtained by solving this model. Conclusions about the reasonable range of grounding impedance will be obtained based on the fault characteristic. The derived model has the following features:

(1) The variation of system state parameters under various fault conditions is simple to acquire by inputting the converter switch state and the system state data in the normal condition.

(2) Compared with traditional models, the proposed system model is more accurate for assessing the system fault characteristics by considering the impact of switch state on the topology of the system fault circuit.

(3) The maximum system fault current under various fault conditions at the dc and ac system is easy to calculate based on the model.

The rest of the paper is organized as follows. Section 2 describes the LVDC supply and utilization system. In Section 3, the derivation of the LVDC supply and utilization system model is introduced in detail. The model solution algorithm is introduced in detail in Section 4. The simulations are performed in Section 5 to verify the effectiveness of the model. In Section 6, the conclusions are summarized.

\section{System Description}

The topology of the simulated LVDC supply and utilization system is shown in Figure 1. Generally, the LVDC supply and utilization system is comprised of source, network, and loads, which is similar to the conventional low voltage AC supply and utilization system. For the source used in LVDC supply and utilization system, renewable energies are recommended and widely accepted. In this paper, PV is adopted as the renewable energy source in the LVDC supply and utilization system. In order to integrate renewable energy into the LVDC supply and utilization system, a boost converter, which adopts the MPPT control strategy [26], is attached to the LVDC bus. For the loads used in the LVDC supply and utilization system, the DC loads are highly recommended for easy connection characteristics. In this paper, a flexible DC load is adopted to simulate the conventional loads in LVDC supply and utilization system such as electric vehicles, DC buildings, and the data center. In addition, an ESS is considered in the LVDC supply and utilization system to mitigate the variability of renewable energy to decrease the power difference between the PV and DC loads. A bidirectional buck-boost converter is configured into the LVDC bus to connect an ESS into the system. The voltage expression of the converter in the AC side can be obtained as:

$$
\left\{\begin{array}{c}
V_{a}(t)=V_{s} \cos (\omega t) \\
V_{b}(t)=V_{s} \cos (\omega t-2 / 3 \pi) \\
V_{c}(t)=V_{s} \cos (\omega t+2 / 3 \pi)
\end{array}\right.
$$

where $V_{s}$ is the voltage amplitude; $\omega$ represents the angular frequency. 


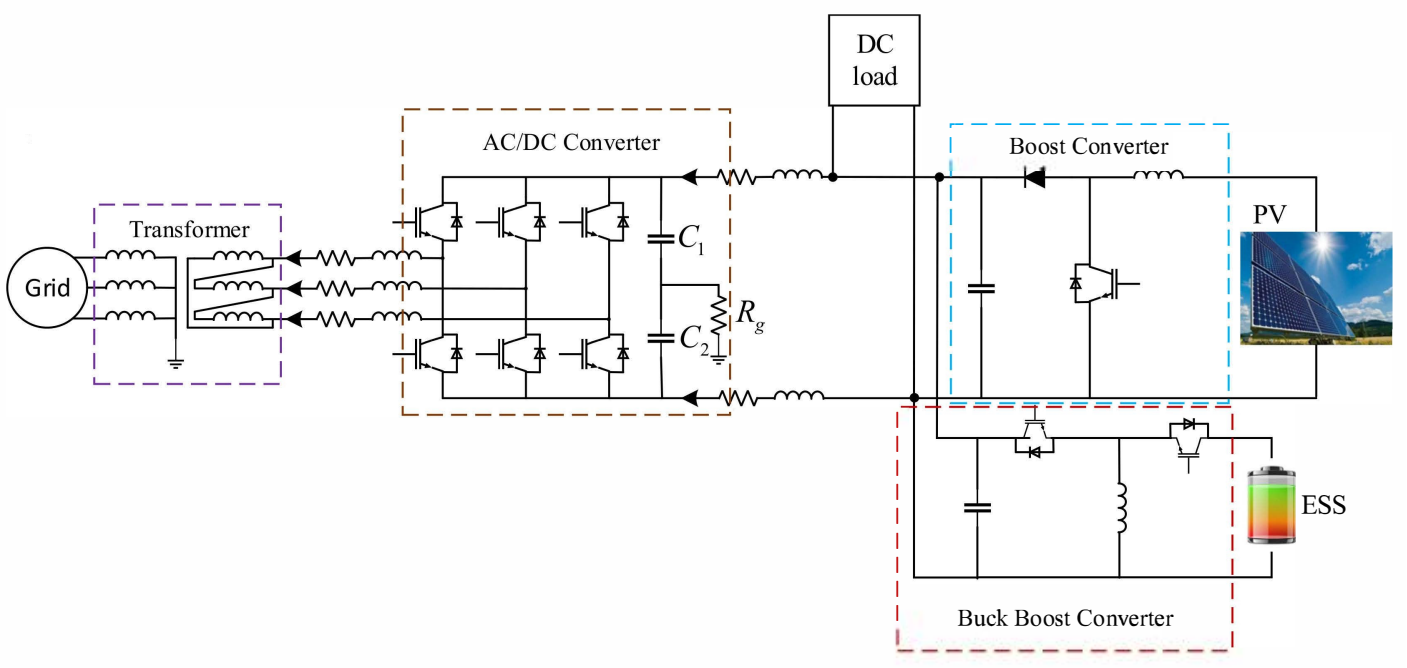

Figure 1. Schematic Diagram of the LVDC supply and utilization system.

There are several typical grounding types in the DC network: DC side insulation from the ground, DC neutral point earthing, DC negative pole earthing, AC side insulation from the ground, AC transformer neutral point earthing. On the DC side, the DC neutral earthing is selected in this system, in which the neutral point capacitor on the DC side is grounded to form a positive and negative symmetrical DC line. On the AC side, the AC transformer neutral point earthing is selected in this system. Additionally, with the aim of realizing galvanic separation, the $\mathrm{Y} / \Delta$ arrangement of the three-phase transformer, with the $\Delta$-connection on the converter-side, is utilized to excludes the zero-sequence and system leakage current [14]. In the following section, a mathematical model of LVDC supply and utilization system will be derived to investigate the impact on the system.

\section{Grounding Fault Model of LVDC Supply and Utilization System}

In this section, the model of LVDC supply and utilization system in various switch states is introduced. The configuration of the three-phase double-level bidirectional AC/DC rectifier is shown in Figure 1. Each rectifier leg is composed of two IGBT switches $S_{u p}$ and $S_{\text {down }}$ with a double antiparallel diode $D_{u p}$ and $D_{\text {down }}$. Each IGBT and antiparallel diode can be employed as the current path under the normal operating condition of the converter. Two DC bus capacitors with the same capacity are utilized to provide a neutral point in the DC side of the converter.

Generally, the DC side capacitor is chosen high enough to make sure the DC poles voltage toward the ground remains at $\pm \mathrm{Vdc} / 2$ value constantly. The $\mathrm{DC}$-link capacitance will be discharged or charged rapidly under the ground fault condition. A large amount of fault current passes through IGBT or diode from the fault point to the capacitor with low impedance, which poses a threat to the LVDC supply and utilization system. Additionally, the voltage of the upper or lower capacitor can reach zeros in the process of discharge, which will cause another capacitor to experience the whole Vdc value.

In this system, the upper switch $S_{x u p}$ and lower switch $S_{x \text { down }}(x=a, b, c)$, are controlled independently in each leg of this AC/DC converter. In order to better describe the switching state of the bidirectional AC/DC rectifier in the LVDC supply and utilization system, a switching state vector is given, which is:

$$
S=\left[S_{1}, S_{2}, S_{3}, S_{4}, S_{5}, S_{6}\right]^{T}
$$

where $S$ is the switching state vector of bidirectional AC/DC converter and the $S_{x}=$ $\{0,1\}(1,2,3,4,5,6)$ is considered as the switching state variable that takes 1 and 0 when the IGBT is ON and OFF, $S_{1}$ and $S_{2}$ are the switching state variables of upper and lower switch in phase A, respectively, $S_{3}$ and $S_{4}$ are the switching state variables of upper and 
lower switch in phase B, respectively, $S_{5}$ and $S_{6}$ are the switching state variables of upper and lower switch in phase $\mathrm{C}$ respectively.

Following constraints are considered to avoid triggering all switches of each leg simultaneously:

$$
\begin{gathered}
S_{1}+S_{2}=1, S_{3}+S_{4}=1, S_{5}+S_{6}=1 \\
S_{1}+S_{3}+S_{5} \geq 1, S_{2}+S_{4}+S_{6} \geq 1
\end{gathered}
$$

By defining the switching state vector, a state-space model of LVDC supply and utilization system in normal condition is proposed at first, which can be described as follows:

$$
A_{0} X(t)=B_{0} \frac{d Y(t)}{d t}+C_{0} Y(t)
$$

where $X(t)=\left[V_{d c}, V_{a b}(t), V_{b c}(t)\right]^{T}$ is the input vector, $Y(t)=\left[I_{a}(t), I_{b}(t), I_{c}(t)\right]^{T}$ is the system state variable, $V_{d c}$ is the DC-link voltage, $V_{a b}(t)$ is the voltage drop between phase $A$ and phase $B$ at the time $t, I_{x}(t)(x=a, b, c)$ is the phase current at time $t, A_{0}, B_{0}$ and $C_{0}$ are the coefficient matrix of the state-space model, which is:

$$
\begin{aligned}
A_{0} & =\left[\begin{array}{ccc}
\alpha_{1}-\alpha_{2} & -1 & 0 \\
\alpha_{3}-\alpha_{4} & 0 & -1 \\
0 & 0 & 0
\end{array}\right] \\
B_{0} & =\left[\begin{array}{ccc}
L_{a} & -L_{b} & 0 \\
0 & L_{b} & -L_{c} \\
1 & 1 & 1
\end{array}\right] \\
C_{0} & =\left[\begin{array}{ccc}
R_{a} & -R_{b} & 0 \\
0 & R_{b} & -R_{c} \\
0 & 0 & 0
\end{array}\right]
\end{aligned}
$$

where $L_{x}(x=a, b, c)$ is the $\mathrm{AC}$ line inductance, $R_{x}(x=a, b, c)$ is the AC line resistance, the parameters $\alpha_{1}, \alpha_{2}, \alpha_{3}, \alpha_{4}$ in the matrix $A_{0}$ can be formulated as follows:

$$
\begin{aligned}
& \alpha_{1}=\frac{\left(S_{1}-S_{3}\right)}{2}, \alpha_{2}=\frac{\left(S_{2}-S_{4}\right)}{2} \\
& \alpha_{3}=\frac{\left(S_{3}-S_{5}\right)}{2}, \alpha_{4}=\frac{\left(S_{4}-S_{6}\right)}{2}
\end{aligned}
$$

According to the state-space equation, the system states in the normal condition can be derived once the switching state is given.

Based on the steady model of LVDC supply and utilization system in the normal condition, the model of LVDC supply and utilization system under various fault conditions can be derived, which consist of single-line-to-ground fault, double-line-to-ground fault, three-line-to-ground fault, positive pole-to-ground fault, negative pole-to-ground fault [27]. The extra current loop will be added to the LVDC supply and utilization system under the fault condition, which leads to the change in matrices and adds an additional parameter into them. Under the fault condition, the voltage of the upper capacitor and lower capacitor on the DC side is not equal, and the AC/DC rectifier will be working inappropriately. Additionally, the fault current is merely supplied from the DC-link capacitor because the AC side of the system converter is isolated from the ground. Therefore, the voltage and current of the capacitor are considered as system state variables in the proposed model. The new system state variable $Y(t)$ is defined as:

$$
Y(t)=\left[I_{a}(t), I_{b}(t), I_{c}(t), I_{f}(t), V_{c 1}(t), V_{c 2}(t), I_{c 1}(t)\right]^{T}
$$


where $I_{f}(t)$ is the fault current at the time $t, V_{c 1}(t)$ is the voltage of the upper capacitor in the DC side at the time $t, V_{c 2}(t)$ is the voltage of the lower capacitor in the DC side at the time $t, I_{c 1}(t)$ is the current of upper capacitor in the DC side at the time $t$.

By defining the new system state variable $Y(t)$, the following model explained the system fault signature:

$$
A_{\varphi} X(t)+D_{\varphi} \frac{d X(t)}{d t}=B_{\varphi} \frac{d Y(t)}{d t}+C_{\varphi} Y(t)
$$

$A_{\varphi}, B_{\varphi}, C_{\varphi}, D_{\varphi}$ are the coefficient matrixes, which will be defined depending on the grounding fault type. In the following, the specific expression of the coefficient matrix is discussed in more detail.

\subsection{Single-Line-to-Ground Fault}

In order to simplify the expression, suppose the single-line-to-ground fault as phase A-to-ground fault. Under the single-line-to-ground fault condition, the phase current of the fault phase can be decomposed into the normal component and the fault component. Therefore, the phase current for phase $\mathrm{A}$ is $I_{a}(t)-I_{f}(t)$, the phase current for phase $\mathrm{B}$ is $I_{b}(t)$, the phase current for phase $C$ is $I_{c}(t)$. The coefficients matrixes under the single-line to ground fault condition are formulated as follows:

$$
\begin{aligned}
& A_{\varphi}=\left[\begin{array}{ccc}
0 & -1 & 0 \\
0 & 0 & -1 \\
0 & 0 & 0 \\
0 & 0 & 0 \\
0 & 0 & 0 \\
1 & 0 & 0 \\
0 & 0 & 0
\end{array}\right] \\
& B_{\varphi}=\left[\begin{array}{ccccccc}
L_{a} & -L_{b} & 0 & -L_{a} & 0 & 0 & 0 \\
0 & L_{b} & -L_{c} & 0 & 0 & 0 & 0 \\
1 & 1 & 1 & 0 & 0 & 0 & 0 \\
L_{a} & 0 & 0 & -L_{a} & 0 & 0 & 0 \\
0 & 0 & 0 & 0 & -C & C & 0 \\
h_{a} L_{d c} & h_{b} L_{d c} & h_{c} L_{d c} & -\left(h_{a}+1\right) L_{d c} & 0 & 0 & 2 L_{d c} \\
0 & 0 & 0 & 0 & -C & 0 & 0
\end{array}\right] \\
& C_{\varphi}=\left[\begin{array}{ccccccc}
R_{a} & -R_{b} & 0 & -R_{a} & -2 \alpha_{1} & 2 \alpha_{2} & 0 \\
0 & R_{b} & -R_{c} & 0 & -2 \alpha_{3} & 2 \alpha_{4} & 0 \\
0 & 0 & 0 & 0 & 0 & 0 & 0 \\
R_{a} & 0 & 0 & -\left(R_{f a}+R_{g}+R_{a}\right) & -S_{1} & S_{2} & 0 \\
0 & 0 & 0 & 1 & 0 & 0 & 0 \\
h_{a} R_{d c} & h_{b} R_{d c} & h_{c} R_{d c} & -\left(h_{a}+1\right) R_{d c} & 1 & 1 & 2 R_{d c} \\
0 & 0 & 0 & 0 & 0 & 0 & 1
\end{array}\right] \\
& D_{\varphi}=[0]
\end{aligned}
$$

where $R_{f a}$ is the fault resistance between the fault point and the ground, $R_{g}$ is the grounding resistance, $R_{d c}$ is the DC side resistance, $L_{d c}$ is the DC side inductance, the parameters $h_{a}$, $h_{b}, h_{c}$ in the matrix $B_{\varphi}$ and $C_{\varphi}$ can be described as follows:

$$
\left\{\begin{array}{l}
h_{a}=S_{1}-S_{2} \\
h_{b}=S_{3}-S_{4} \\
h_{c}=S_{5}-S_{6}
\end{array}\right.
$$




\subsection{Double-Line-to-Ground Fault}

Given that the double-line-to-ground fault as phase A to phase B-to-ground fault for the reduced expression. Therefore, the phase current for phase $\mathrm{A}$ is $I_{a}(t)+V_{a b}(t) / R_{a b}$, the phase current for phase B is $I_{b}(t)-\frac{V_{a b}(t)}{R_{a b}}-I_{f}(t)$, the phase current for phase $C$ is $I_{c}(t)$. The coefficients matrixes under the single-line-to-ground fault condition are formulated as follows:

$$
\begin{aligned}
& A_{\varphi}=\left[\begin{array}{ccc}
0 & -\left(1+\frac{2 R_{b}}{R_{a b}}\right) & 0 \\
0 & \frac{R_{b}}{R_{a b}} & -1 \\
0 & 0 & 0 \\
0 & \frac{R_{b}}{R_{a b}} & 0 \\
0 & 0 & 0 \\
1 & -\left(h_{a}-h_{b}\right) \frac{R_{d c}}{R_{a b}} & 0 \\
0 & 0 & 0
\end{array}\right] \\
& B_{\varphi}=\left[\begin{array}{ccccccc}
L_{a} & -L_{b} & 0 & L_{b} & 0 & 0 & 0 \\
0 & L_{b} & -L_{c} & -L_{b} & 0 & 0 & 0 \\
1 & 1 & 1 & 0 & 0 & 0 & 0 \\
0 & L_{b} & 0 & -L_{b} & 0 & 0 & 0 \\
0 & 0 & 0 & 0 & -C & C & 0 \\
h_{a} L_{d c} & h_{b} L_{d c} & h_{c} L_{d c} & -\left(h_{b}+1\right) L_{c} & 0 & 0 & 2 L_{d c} \\
0 & 0 & 0 & 0 & -C & 0 & 0
\end{array}\right] \\
& C_{\varphi}=\left[\begin{array}{ccccccc}
R_{a} & -R_{b} & 0 & R_{b} & -2 \alpha_{1} & 2 \alpha_{2} & 0 \\
0 & R_{b} & -R_{c} & -R_{b} & -2 \alpha_{3} & 2 \alpha_{4} & 0 \\
0 & 0 & 0 & 0 & 0 & 0 & 0 \\
0 & R_{b} & 0 & -\left(R_{f b}+R_{g}+R_{b}\right) & -S_{3} & S_{4} & 0 \\
0 & 0 & 0 & 1 & 0 & 0 & 0 \\
h_{a} R_{d c} & h_{b} R_{d c} & h_{c} R_{d c} & -\left(h_{b}+1\right) R_{d c} & 1 & 1 & 2 R_{d c} \\
0 & 0 & 0 & 0 & 0 & 0 & 1
\end{array}\right] \\
& D_{\varphi}=\left[\begin{array}{ccc}
0 & \frac{-2 L_{b}}{R_{a b}} & 0 \\
0 & \frac{L_{b}}{R_{a b}} & 0 \\
0 & 0 & 0 \\
0 & \frac{L_{b}}{R_{a b}} & 0 \\
0 & 0 & 0 \\
0 & -\left(h_{a}-h_{b}\right) \frac{L_{d c}}{R_{a b}} & 0 \\
0 & 0 & 0
\end{array}\right]
\end{aligned}
$$

where $R_{f b}$ is the fault resistance between the fault point and the ground, $R_{a b}$ is the fault resistance between phase A and phase B.

$$
A_{\varphi}=\left[\begin{array}{ccc}
0 & -\left(1+\frac{2 R_{b}}{R_{a b}}\right) & 0 \\
0 & \frac{R_{b}}{R_{a b}} & -1 \\
0 & 0 & 0 \\
0 & \frac{R_{b}}{R_{a b}} & 0 \\
0 & 0 & 0 \\
1 & -\left(h_{a}-h_{b}\right) \frac{R_{d c}}{R_{a b}} & 0 \\
0 & 0 & 0
\end{array}\right]
$$




$$
\begin{gathered}
B_{\varphi}=\left[\begin{array}{ccccccc}
L_{a} & -L_{b} & 0 & L_{b} & 0 & 0 & 0 \\
0 & L_{b} & -L_{c} & -L_{b} & 0 & 0 & 0 \\
1 & 1 & 1 & 0 & 0 & 0 & 0 \\
0 & L_{b} & 0 & -L_{b} & 0 & 0 & 0 \\
0 & 0 & 0 & 0 & -C & C & 0 \\
h_{a} L_{d c} & h_{b} L_{d c} & h_{c} L_{d c} & -\left(h_{b}+1\right) L_{c} & 0 & 0 & 2 L_{d c} \\
0 & 0 & 0 & 0 & -C & 0 & 0
\end{array}\right] \\
C_{\varphi}=\left[\begin{array}{ccccccc}
R_{a} & -R_{b} & 0 & R_{b} & -2 \alpha_{1} & 2 \alpha_{2} & 0 \\
0 & R_{b} & -R_{c} & -R_{b} & -2 \alpha_{3} & 2 \alpha_{4} & 0 \\
0 & 0 & 0 & 0 & 0 & 0 & 0 \\
0 & R_{b} & 0 & -\left(R_{f b}+R_{g}+R_{b}\right) & -S_{3} & S_{4} & 0 \\
0 & 0 & 0 & 1 & 0 & 0 & 0 \\
h_{a} R_{d c} & h_{b} R_{d c} & h_{c} R_{d c} & -\left(h_{b}+1\right) R_{d c} & 1 & 1 & 2 R_{d c} \\
0 & 0 & 0 & 0 & 0 & 0 & 1
\end{array}\right] \\
D_{\varphi}=\left[\begin{array}{ccc}
0 & \frac{-2 L_{b}}{R_{a b}} & 0 \\
0 & \frac{L_{b}}{R_{a b}} & 0 \\
0 & 0 & 0 \\
0 & \frac{L_{b}}{R_{a b}} & 0 \\
0 & 0 & 0 \\
0 & -\left(h_{a}-h_{b}\right) \frac{L_{d c}}{R_{a b}} & 0 \\
0 & 0 & 0
\end{array}\right]
\end{gathered}
$$

where $R_{f b}$ is the fault resistance between the fault point and the ground, $R_{a b}$ is the fault resistance between phase A and phase B.

\subsection{Three-Line-to-Ground Fault}

In the case of the three-line-to-ground fault occurrence. The phase current is $I_{a}(t)+$ $V_{a b}(t) / R_{a b}, I_{b}(t)-\frac{V_{a b}(t)}{R_{a b}}+\frac{V_{b c}(t)}{R_{b c}}, I_{c}(t)-\frac{V_{b c}(t)}{R_{b c}}-I_{f}(t)$, respectively. The coefficients matrices under three-line-to-ground fault condition are formulated as follows:

$$
\begin{aligned}
& A_{\varphi}=\left[\begin{array}{ccc}
0 & -\left(1+\frac{2 R_{b}}{R_{a b}}\right) & \frac{R_{c}}{R_{b c}} \\
0 & \frac{R_{b}}{R_{a b}} & -\left(1+2 \frac{R_{c}}{R_{b c}}\right) \\
0 & 0 & 0 \\
0 & 0 & \frac{R_{c}}{R_{b c}} \\
0 & 0 & 0 \\
1 & -\left(h_{a}-h_{b}\right) \frac{R_{d c}}{R_{a b}} & -\left(h_{b}-h_{c}\right) \frac{R_{d c}}{R_{b c}} \\
0 & 0 & 0
\end{array}\right] \\
& B_{\varphi}=\left[\begin{array}{ccccccc}
L_{a} & -L_{b} & 0 & 0 & 0 & 0 & 0 \\
0 & L_{b} & -L_{c} & L_{c} & 0 & 0 & 0 \\
1 & 1 & 1 & 0 & 0 & 0 & 0 \\
0 & 0 & L_{c} & -L_{c} & 0 & 0 & 0 \\
0 & 0 & 0 & 0 & -C & C & 0 \\
h_{a} L_{d c} & h_{b} L_{d c} & h_{c} L_{d c} & -\left(h_{c}+1\right) L_{d c} & 0 & 0 & 2 L_{d c} \\
0 & 0 & 0 & 0 & -C & 0 & 0
\end{array}\right]
\end{aligned}
$$




$$
\begin{gathered}
C_{\varphi}=\left[\begin{array}{ccccccc}
R_{a} & -R_{b} & 0 & 0 & -2 \alpha_{1} & 2 \alpha_{2} & 0 \\
0 & R_{b} & -R_{c} & R_{c} & -2 \alpha_{3} & 2 \alpha_{4} & 0 \\
0 & 0 & 0 & 0 & 0 & 0 & 0 \\
0 & R_{b} & 0 & -\left(R_{f c}+R_{g}+R_{c}\right) & -S_{5} & S_{6} & 0 \\
0 & 0 & 0 & 1 & 0 & 0 & 0 \\
h_{a} R_{d c} & h_{b} R_{d c} & h_{c} R_{d c} & -\left(h_{c}+1\right) R_{d c} & 1 & 1 & 2 R_{d c} \\
0 & 0 & 0 & 0 & 0 & 0 & 1
\end{array}\right] \\
D_{\varphi}=\left[\begin{array}{cccc}
0 & \frac{-2 L_{b}}{R_{a b}} & \frac{L_{c}}{R_{b c}} \\
0 & \frac{L_{b}}{R_{a b}} & \frac{-2 L_{c}}{R_{b c}} \\
0 & 0 & 0 & \\
0 & 0 & \frac{L_{c}}{R_{b c}} \\
0 & 0 & 0 \\
0 & -\left(h_{a}-h_{b}\right) \frac{L_{d c}}{R_{a b}} & -\left(h_{b}-h_{c}\right) \frac{L_{d c}}{R_{b c}} \\
0 & 0 & 0
\end{array}\right]
\end{gathered}
$$

\subsection{Positive Pole-to-Ground Fault}

Given that a ground fault occurrence in the positive pole, the coefficients matrices are formulated as:

$$
\begin{aligned}
& A_{\varphi}=\left[\begin{array}{ccc}
0 & -1 & 0 \\
0 & 0 & -1 \\
0 & 0 & 0 \\
0 & 0 & 0 \\
0 & 0 & 0 \\
1 & 0 & 0 \\
0 & 0 & 0
\end{array}\right] \\
& B_{\varphi}=\left[\begin{array}{ccccccc}
L_{a} & -L_{b} & 0 & 0 & 0 & 0 & 0 \\
0 & L_{b} & -L_{c} & 0 & 0 & 0 & 0 \\
1 & 1 & 1 & 0 & 0 & 0 & 0 \\
S_{1} L_{d c} & S_{3} L_{d c} & S_{5} L_{d c} & 0 & 0 & 0 & L_{d c} \\
0 & 0 & 0 & 0 & -C & C & 0 \\
h_{a} L_{d c} & h_{b} L_{d c} & h_{c} L_{d c} & -L_{d c} & 0 & 0 & 2 L_{d c} \\
0 & 0 & 0 & 0 & -C & 0 & 0
\end{array}\right] \\
& C_{\varphi}=\left[\begin{array}{ccccccc}
R_{a} & -R_{b} & 0 & 0 & -2 \alpha_{1} & 2 \alpha_{2} & 0 \\
0 & R_{b} & -R_{c} & 0 & -2 \alpha_{3} & 2 \alpha_{4} & 0 \\
0 & 0 & 0 & 0 & 0 & 0 & 0 \\
S_{1} R_{d c} & S_{3} R_{d c} & S_{5} R_{d c} & \left(R_{f p}+R_{g}+R_{d c}\right) & 1 & 0 & R_{d c} \\
0 & 0 & 0 & 1 & 0 & 0 & 0 \\
h_{a} R_{d c} & h_{b} R_{d c} & h_{c} R_{d c} & -R_{d c} & 1 & 1 & 2 R_{d c} \\
0 & 0 & 0 & 0 & 0 & 0 & 1
\end{array}\right] \\
& D_{\varphi}=[0]
\end{aligned}
$$

\subsection{Negative Line-to-Ground Fault}

In case of a ground fault occurrence in the negative pole, the coefficients matrices are described as:

$$
A_{\varphi}=\left[\begin{array}{ccc}
0 & -1 & 0 \\
0 & 0 & -1 \\
0 & 0 & 0 \\
0 & 0 & 0 \\
0 & 0 & 0 \\
1 & 0 & 0 \\
0 & 0 & 0
\end{array}\right]
$$




$$
\begin{aligned}
& B_{\varphi}=\left[\begin{array}{ccccccc}
L_{a} & -L_{b} & 0 & 0 & 0 & 0 & 0 \\
0 & L_{b} & -L_{c} & 0 & 0 & 0 & 0 \\
1 & 1 & 1 & 0 & 0 & 0 & 0 \\
S_{2} L_{d c} & S_{4} L_{d c} & S_{6} L_{d c} & L_{d c} & 0 & 0 & -L_{d c} \\
0 & 0 & 0 & 0 & -C & C & 0 \\
h_{a} L_{d c} & h_{b} L_{d c} & h_{c} L_{d c} & -L_{d c} & 0 & 0 & 2 L_{d c} \\
0 & 0 & 0 & 0 & -C & 0 & 0
\end{array}\right] \\
& C_{\varphi}=\left[\begin{array}{ccccccc}
R_{a} & -R_{b} & 0 & 0 & -2 \alpha_{1} & 2 \alpha_{2} & 0 \\
0 & R_{b} & -R_{c} & 0 & -2 \alpha_{3} & 2 \alpha_{4} & 0 \\
0 & 0 & 0 & 0 & 0 & 0 & 0 \\
S_{2} R_{d c} & S_{4} R_{d c} & S_{6} R_{d c} & \left(R_{f n}+R_{g}+R_{d c}\right) & 0 & -1 & -R_{d c} \\
0 & 0 & 0 & 1 & 0 & 0 & 0 \\
h_{a} R_{d c} & h_{b} R_{d c} & h_{c} R_{d c} & -R_{d c} & 1 & 1 & 2 R_{d c} \\
0 & 0 & 0 & 0 & 0 & 0 & 1
\end{array}\right] \\
& D_{\varphi}=[0]
\end{aligned}
$$

The fault signature under various fault conditions with different switching states of the AC/DC converter is obtained by solving this model, which can reflect the effect of the ground fault on the LVDC supply and utilization system.

\section{Model Solution Algorithm}

\subsection{Fourth-Order Runge-Kutta Method}

The exact expression of the solution is very difficult to acquired because Equation (12) is highly complicated. To overcome this problem, the Fourth-order Runge-Kutta method is utilized to obtain the accurate value at some point by inputting the initial value rather than the exact expression.

The Fourth-order Runge-Kutta method is a high-precision single-step algorithm widely used to solve differential equations [28,29]. Based on this method, the system data can be easily acquired with a piece of coed according to mathematical programming software.

This method is generally expressed as follows:

$$
Y_{n+1}=Y_{n}+\frac{t_{h}}{6}\left(k_{1}+2 k_{2}+2 k_{3}+k_{4}\right)
$$

where $Y_{n}$ is the value of system state variables at the time $t_{n}, t_{h}$ is the time interval for each iteration, $k_{1}, k_{2}, k_{3}, k_{4}$ are the variation coefficient of the system state variables, which can be formulated as follows:

$$
\begin{gathered}
k_{1}=f\left(Y_{n}, t_{n}\right) \\
k_{2}=f\left(Y_{n}+t_{h} \frac{k_{1}}{2}, t_{n}+\frac{t_{h}}{2}\right) \\
k_{3}=f\left(Y_{n}+t_{h} \frac{k_{2}}{2}, t_{n}+\frac{t_{h}}{2}\right) \\
k_{4}=f\left(Y_{n}+t_{h} k_{3}, t_{n}+t_{h}\right)
\end{gathered}
$$

\subsection{Model Solution Algorithm Flowchart}

The switch state of the converter at some point is unknown because it depends on the control strategy. Therefore, the Monte Carlo method is utilized to simulate the switching state during the fault time to estimate the maximum fault current [30].

The flowchart of the model solution algorithm for the proposed model is shown in Figure 2. The algorithm mainly includes the following steps: 


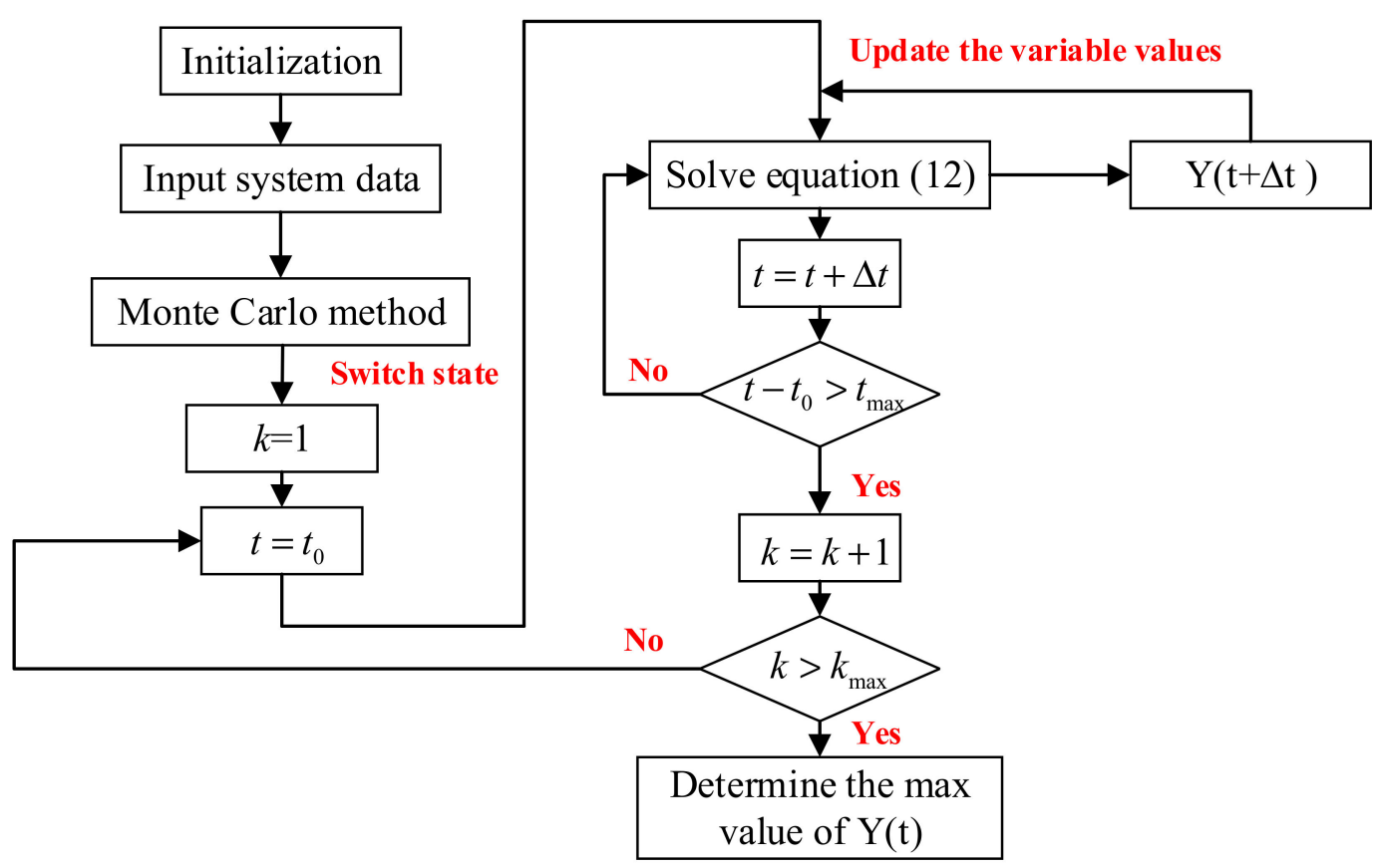

Figure 2. Flowchart of the model solution algorithm.

Step 1: Initialize system parameters and input the system data, such as parameters of lines impedance, capacitor and grounding resistance, DC-link voltage, AC side voltage, and DG output power.

Step 2: Use the Monte Carlo method to generate a random system switch state sequence during fault time. Let the $k$ equal 1.

Step 3: Let the $t$ equal to $t_{0}$ and then input the system state variable initial value $t_{0}$.

Step 4: Utilizing the Fourth-order Runge-Kutta method to obtain the system state variable at $t+\Delta t$ according to generated $k$-th switch state sequence.

Step 5: Update the system state variable initial value. Let the $t_{0}$ equal to $t_{0}+\Delta t$. If the $t-t_{0}>t_{\max }$, go to step 6 , otherwise go to step 4 .

Step 6: Let the $k$ equal to $k+1$. If the $k>k_{\max }$, the calculation is done, determine the max value of $Y(t)$ during the fault time for each generated bidirectional converter switch state sequences. Otherwise, go to step 3.

\section{Result and Discussion}

The studied LVDC supply and utilization system is illustrated in Figure 1, where renewable energy, ESS and the DC load are interconnected through a LVDC bus. The specific detail of the system is discussed in Section 2. The connected photovoltaic array in the LVDC supply and utilization system contains $66 \times 5$ photovoltaic panels. The total power of the photovoltaic array is $120 \mathrm{~kW}$ with LVDC bus voltage of $750 \mathrm{~V}$. The system total DC load contains EV, and household appliances are $100 \mathrm{~kW}$. The remaining power generated by renewable energy is transferred to the connected upper grid through the three-phase double-level bidirectional AC/DC converter under the normal condition. The system parameter of the proposed model is shown in Table 1.

Since the main purpose is to study system fault signature under various fault conditions, the maximum fault current is indicated with various values of grounding resistance from $0 \Omega$ to $8 \Omega$. Therefore, the model described in Section 3 is utilized to simulate the system by considering the various study case, which is shown in Table 2. 
Table 1. System Parameter of the LVDC supply and utilization system.

\begin{tabular}{cc}
\hline Parameters & Value \\
\hline DC voltage & $750 \mathrm{~V}$ \\
AC voltage & $380 \mathrm{~V}$ \\
Transformer ratio & $10 \mathrm{kV} / 380 \mathrm{~V}$ \\
DC side Resistance & $0.01 \Omega$ \\
DC side Inductance & $0.01 \mathrm{mH}$ \\
DC Capacitor & $56 \mathrm{mF}$ \\
AC side Resistance & $0.01 \Omega$ \\
AC side Inductance & $0.01 \mathrm{H}$ \\
\hline
\end{tabular}

Table 2. Study Case.

\begin{tabular}{cc}
\hline Study Case & Fault Condition \\
\hline Case 1 & Single-line-to-ground fault \\
Case 2 & Double-lines-to-ground fault \\
Case 3 & Three-lines-to-ground fault \\
Case 4 & Positive pole-to-ground fault \\
Case 5 & Negative pole-to-ground fault \\
\hline
\end{tabular}

The simulation time of the proposed system model elapsed $0.03 \mathrm{~s}$ under the AC ground fault condition and $0.1 \mathrm{~s}$ under the DC ground fault condition, respectively. Additionally, a simulation is carried out in PSCAD/EMTDC in order to verify the effectiveness of this model.

\subsection{Validation of LVDC Supply and Utilization System Grounding Fault Model}

A comparative study between the fault model and the simulation model is employed to verify the validation of the proposed model. In order to better verify the effectiveness of the proposed method, the grounding resistance was set in $0 \Omega$, which will be greater than 0 in the actual condition. The system parameter adopted in both models is shown in Table 1. The comparison results of fault current under various study cases are illustrated in Figures 3-7.

Figures $3-5$ are the variation of fault current during fault time under the single-lineto-ground fault, double-lines-to-ground fault, and three-lines-to-ground fault condition, respectively. Although the converter switch state's impact on the topology of the fault circuit is considered in the proposed model, the converter's actual switch state is difficult to acquire. Thus, the fault current is calculated with a random switch state in the proposed model while the simulation model is carried out with an accurate converter switch state. However, the fault current acquired by the proposed model without considering the modulation matches well with that of the simulation model. Figures 6 and 7 are the variation of fault current under the positive pole-to-ground fault and negative pole to a ground fault condition, respectively. The fault characteristics of the proposed model are almost exactly the same as that of the simulation model because the switch state has almost no impact on the fault circuit under the DC side to the ground fault condition.

Combining Figures 3-7, it is concluded that the fault current acquired by the proposed model is accurate and adequate for the fault characteristics analysis. Additionally, two overall outcomes can be concluded regarding the fault current characteristic. First, the fault current mainly supplied by DC-link capacitor has the same variation trend under various fault conditions. Second, compared with the DC ground fault, the discharge process under the AC side ground fault is relatively slow due to the change of converter switch state. 


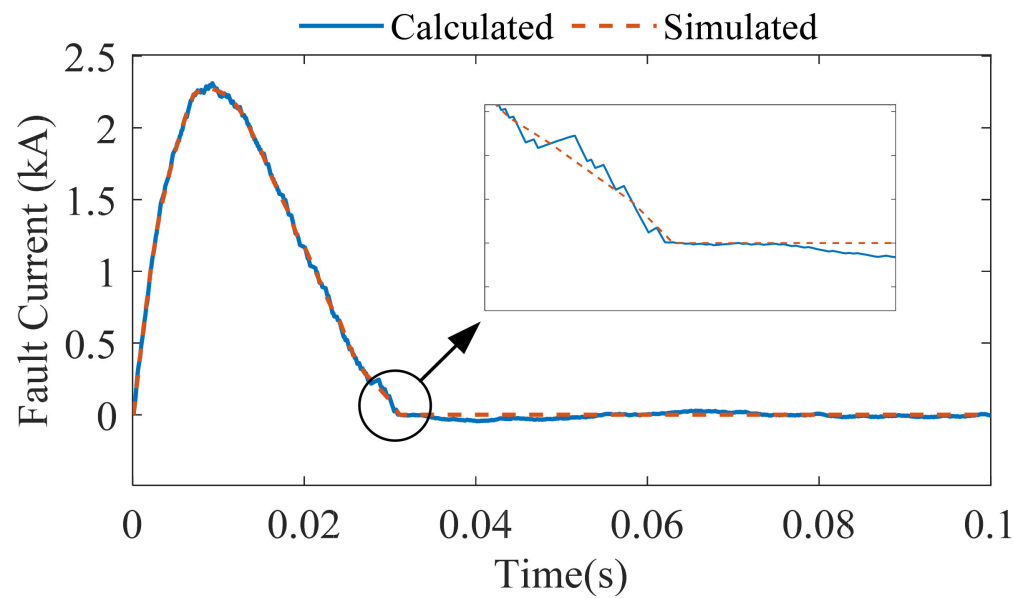

Figure 3. Fault current waveforms in case of single-line-to-ground fault $\left(R_{g}=0 \Omega\right)$.

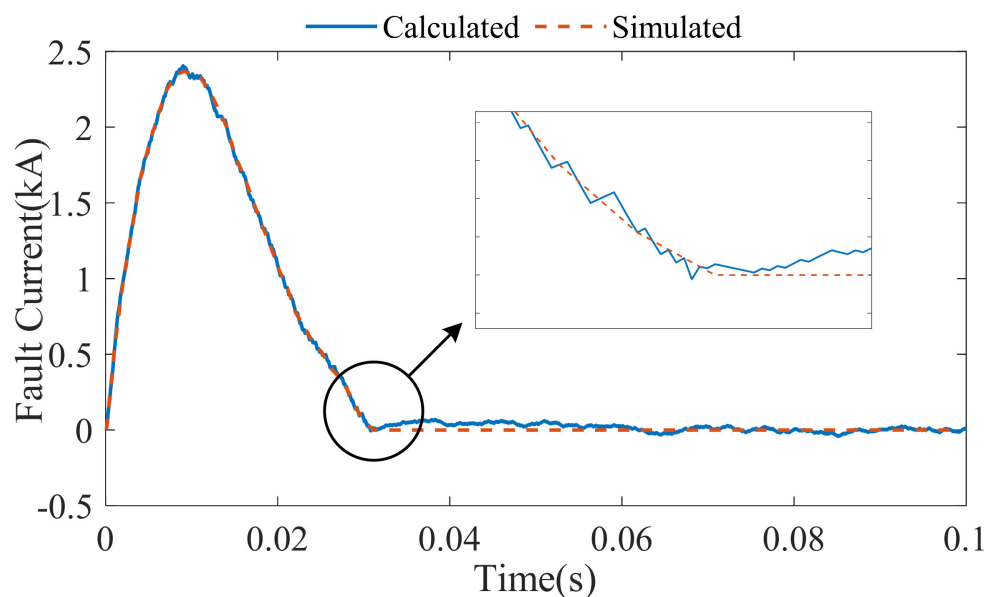

Figure 4. Fault current waveforms in case of double-lines-to-ground fault $\left(R_{g}=0 \Omega\right)$.

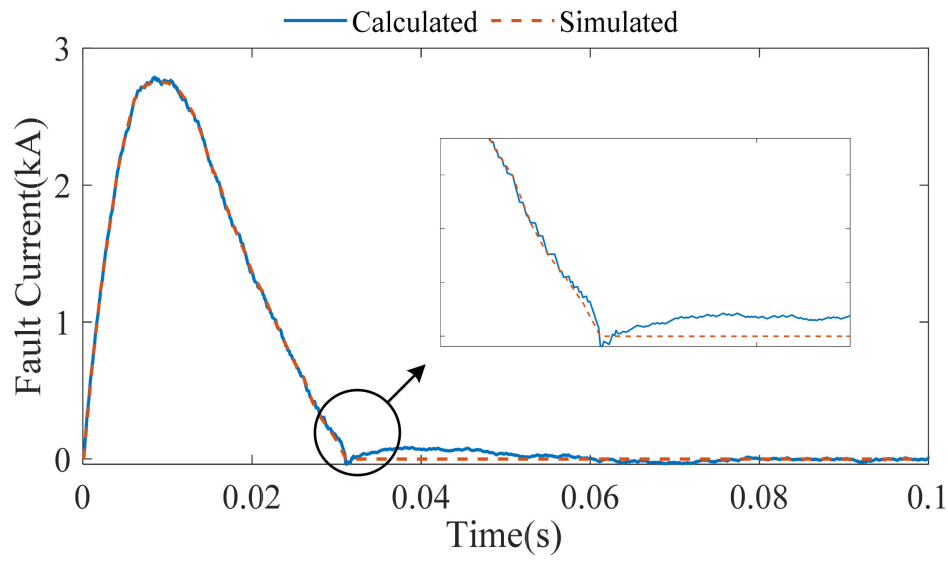

Figure 5. Fault current waveforms in case of three-lines-to-ground fault $\left(R_{g}=0 \Omega\right)$. 


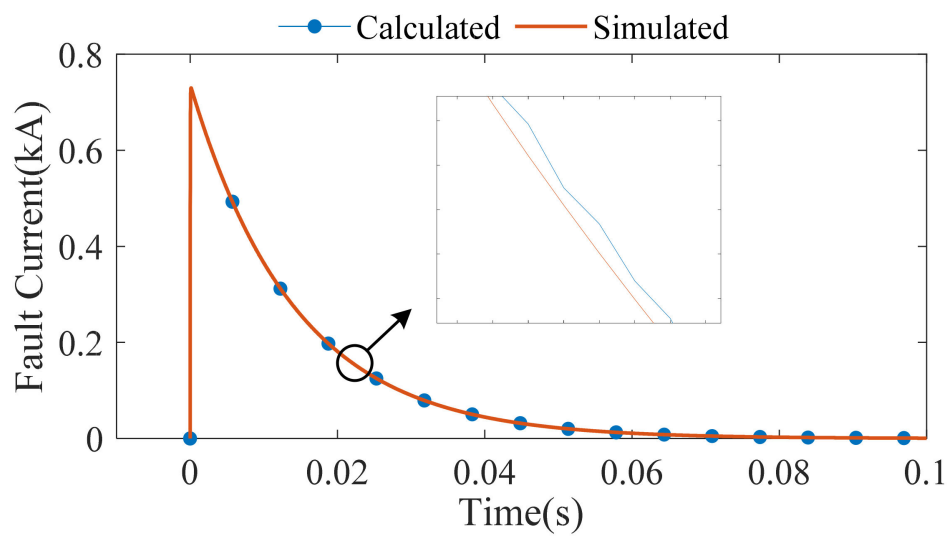

Figure 6. Fault current waveforms in case of the positive pole-to-ground fault $\left(R_{g}=0 \Omega\right)$.

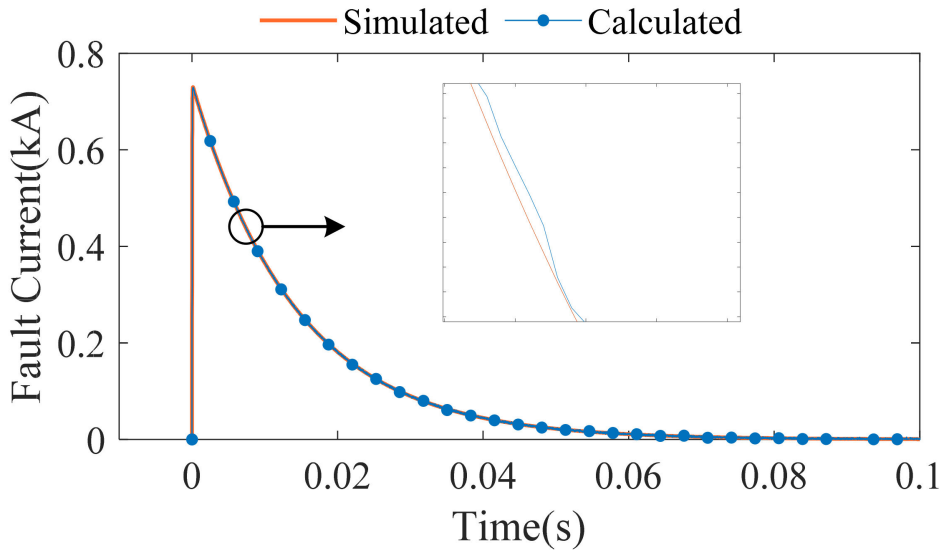

Figure 7. Fault current waveforms in case of the negative pole-to-ground fault $\left(R_{g}=0 \Omega\right)$.

\subsection{Influence of Grounding Resistance}

With the aim of studying system fault signature under various fault conditions, the maximum fault current with the variation of grounding resistance is calculated by the proposed model solution algorithm and PSCAD/EMTDC, respectively. The maximum fault current under various study cases with various values of grounding resistance from $0 \Omega$ to $8 \Omega$ are shown in Figures 8-12.

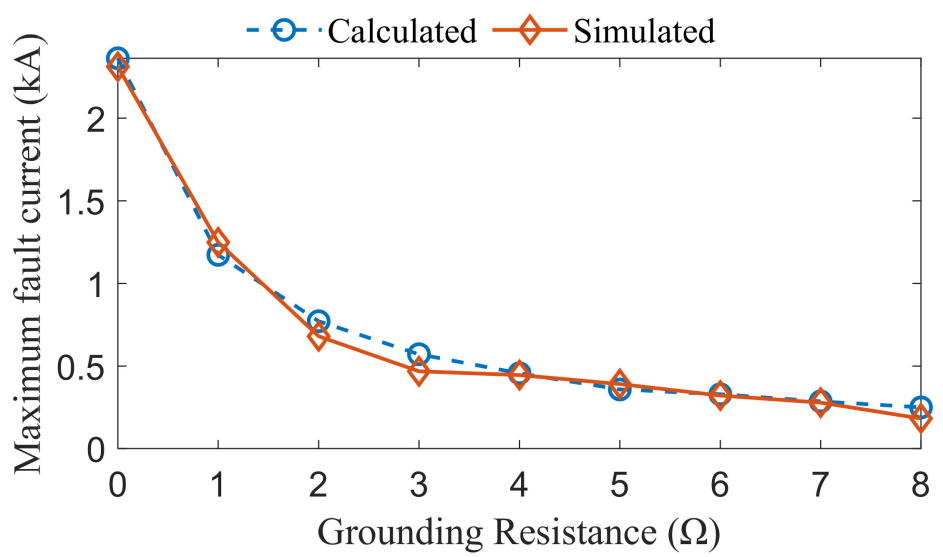

Figure 8. Maximum fault current under the single-line to the ground fault condition. 


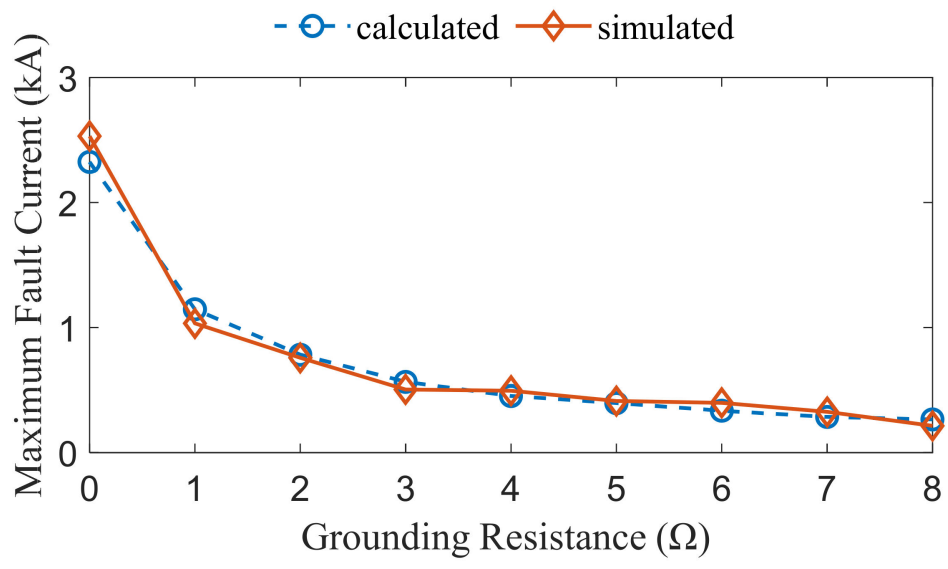

Figure 9. Maximum fault current under the double-line to the ground fault condition.

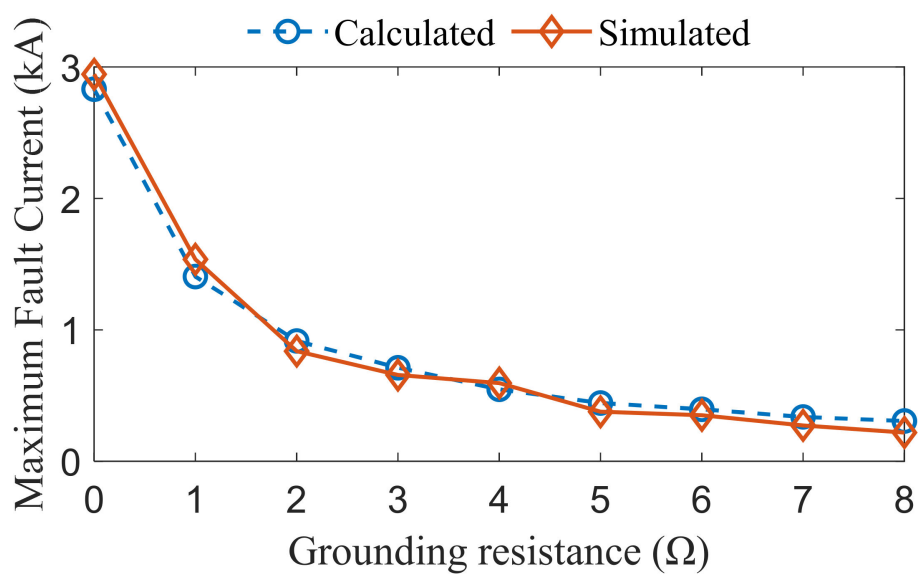

Figure 10. Maximum fault current under three-line-to-ground fault condition.

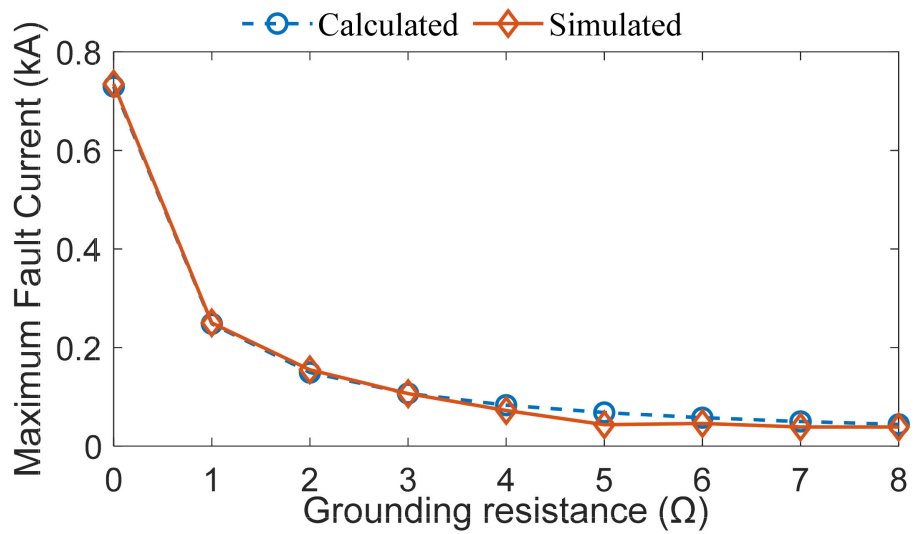

Figure 11. Maximum fault current under the positive pole to the ground fault condition. 


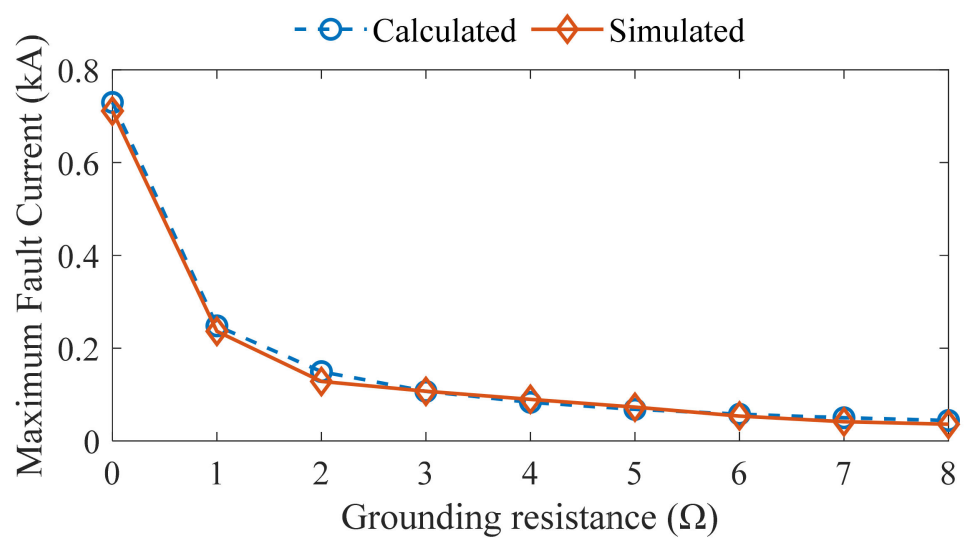

Figure 12. Maximum fault current under the negative pole to the ground fault condition.

\subsubsection{Case 1: Single-Line-to-Ground Fault}

Under the single-line-to-ground fault condition, if the upper switch in phase A is on, the upper capacitor will discharge rapidly through the fault circuit consisting of grounding resistance, fault resistance, and AC line impedance. If the lower switch in phase A is on, the lower capacitor will discharge rapidly through the fault circuit. Figure 8 shows the comparison of the maximum calculated and simulated fault current with various grounding resistances from $0 \Omega$ to $8 \Omega$. When the grounding resistance $R_{g}$ is $0 \Omega$, the maximum fault current calculated by the proposed model reaches $2300 \mathrm{~A}$, whereas the system current under the normal condition is $360 \mathrm{~A}$. The maximum fault current drops sharply in low $R_{g}$ with the growth of the $R_{g}$. However, this trend is not obvious if the $R_{g}$ is more than $3 \Omega$. Without considering the converter switch state, the calculated maximum fault matches highly with the simulated results, which verifies the effectivity of the model.

\subsubsection{Case 2: Double-Lines-to-Ground Fault}

Under the double-lines to a ground fault condition, the fault circuit is more complex. The fault circuit consists of grounding resistance, the fault resistance between phase A and $\mathrm{B}$, grounding fault resistance, and the $\mathrm{AC}$ line impedance between phase $\mathrm{A}$ and $\mathrm{B}$. The upper and lower capacitor will discharge at the same time through the fault circuit if $\mathbf{S} \_1+S_{-} 3=1$. The comparison of the calculated and simulated fault current in the double-line-to-ground fault condition is illustrated in Figure 9. The maximum fault current will be 2600 A when the grounding resistance $R_{g}$ is equal to $0 \Omega$. With the increase in the resistance, the maximum fault current decreases sharply. The maximum fault current will reduce to 600 A when $R_{g}$ increase to $3 \Omega$. This reduction is not obvious for $R_{g}$ bigger than $3 \Omega$.

\subsubsection{Case 3: Three-Lines-to-Ground Fault}

The fault circuit is most sophisticated under the three-lines-to-ground fault conditions. The fault circuit consists of grounding resistance, the fault resistance between phase $\mathrm{A}$ and $\mathrm{B}$, the fault resistance between phase $\mathrm{B}$ and $\mathrm{C}$, grounding fault resistance, and the AC line impedance between phase A, B and C. The upper and lower capacitor will discharge rapidly at the same time in any converter switch state, which has a remarkable impact on the LVDC supply and utilization system voltage stability. As shown in Figure 10, the maximum fault current under the three-line-to-ground fault condition has the same change trend as that under the single-line-to-ground fault and double-line-to-ground fault condition with the variation of $R_{g}$ from $0 \Omega$ to $8 \Omega$.

\subsubsection{Case 4 and Case 5: DC Ground Fault}

Under the DC ground fault condition, the capacitor in the DC side will discharge quickly through the fault circuit consisting of grounding resistance, fault resistance and 
DC line impedance without considering the converter switch state. The comparison of the maximum calculated and simulated fault current with various values of the grounding resistance from $0 \Omega$ to $8 \Omega$ is illustrated in Figures 11 and 12. Under the DC fault condition, the grounding resistance is $0 \Omega$ when the maximum fault current reaches approximately $720 \mathrm{~A}$. With the growth of the $R_{g}$, the maximum fault current flow through the fault circuit is reduced.

It can be concluded from these results that the system grounding resistance should not be very low because the system will experience severe transient current under various fault conditions. However, excessive system grounding resistance will lead to low fault current, which is difficult to detect with the occurrence of fault in the LVDC supple and utilization system. Therefore, the system grounding resistance selection should depend on the actual situations and specific engineering needs.

\subsection{Discussion}

Fault analysis is significant for the system grounding type selection, which has significant impacts on the system operation stability. However, the existing fault analysis about LVDC mainly depends on simulation software such as MATLAB/Simulink and PSCAD/EMTDC, which can be time-consuming for complicated networks. Therefore, an LVDC supply and utilization system model is proposed for analyzing the system fault characteristics.

The effectiveness of the proposed model is verified in this section. As numerical results illustrate, the system fault feature can be easily acquired by solving the proposed model with a piece of code with a low computational burden. Additionally, the calculated result can offer theoretical guidance for improving the system transient stability. It can be seen from Figures 8-12 that the capacitor on the DC side will discharge quickly through the fault circuit without under the DC ground fault condition without considering the switch state, so the maximum fault current is relatively small. However, the converter switch state has a significant impact on the fault circuit under the AC ground fault condition, the upper and lower capacitors may discharge alternately with a relatively slow process, which leads to a large fault current. In the case of AC ground fault occurrence, the fault current will be affected by the converter switch state, online adjustment of the converter switch state according to the calculated fault current is a reasonable remedy in fault condition to protect the system.

\section{Conclusions}

In this paper, a grounding fault model of the LVDC supply and utilization system was derived for the study of the system fault characteristic under various fault conditions. The proposed model has the following features:

(1) The model is capable of studying the variation of system state parameters under various fault conditions by inputting system state data in normal conditions.

(2) The impact of the AC/DC converter switch state on the topology of the fault circuit is considered in this model.

(3) The calculated results of the proposed system model are accurate and adequate for the fault characteristics analysis, which is validated by the PSCAD/EMTDC simulation results under various fault conditions.

The result confirmed that grounding resistance has a considerable impact on the maximum fault current experience by the LVDC system under various fault conditions. For instance, if the system was solidly grounded, the maximum fault current that appeared at the single-line-to-ground fault condition was $2300 \mathrm{~A}$. The maximum fault current at the single-line-to-ground fault condition was approximately $500 \mathrm{~A}$ when the resisitance was set in $8 \Omega$. Additionally, the system model can provide the basis for the study on the variation of system state parameters in various fault conditions to improve the transient stability of the system with the occurrence of the ground fault. The fault characteristic of the LVDC supply and utilization system can be obtained as long as the system state 
variables can be accurately calculated. The proposed model is only suitable for the system with the IT-AC and the neutral earthing on the DC side, the model about other grounding structure should be more discussed and studied as future work.

Author Contributions: Conceptualization, J.L., K.S. and Z.M.; writing-original draft preparation, J.L., K.S. and Z.L.; writing-review and editing, J.L. and K.S.; visualization, K.L. and Z.L.; supervision, K.L. funding acquisition, K.L. All authors have read and agreed to the published version of the manuscript.

Funding: This work is supported primarily by the National Natural Science Foundation of China under Grant 51777116.

Conflicts of Interest: The authors declare no conflict of interest.

\section{References}

1. Sun, K.; Xiao, H.; Pan, J.; Liu, Y. VSC-HVDC Interties for Urban Power Grid Enhancement. IEEE Trans. Power Syst. 2021, 36, 4745-4753. [CrossRef]

2. Massignan, J.A.D.; Pereira, B.R.; London, J.B.A. Load Flow Calculation with Voltage Regulators Bidirectional Mode and Distributed Generation. IEEE Trans. Power Syst. 2017, 32, 1576-1577.

3. Huang, S.; Hsieh, S.; Wan, H. Confirming the Permissible Capacity of Distributed Generation for Grid-Connected Distribution Feeders. IEEE Trans. Power Syst. 2015, 30, 540-541. [CrossRef]

4. Abaza, A.; El-Sehiemy, R.; Mahmoud, K.; Lehtonen, M.; Darwish, M. Optimal Estimation of Proton Exchange Membrane Fuel Cells Parameter Based on Coyote Optimization Algorithm. Appl. Sci. 2021, 11, 2052. [CrossRef]

5. Abbas, A.S.; El-Sehiemy, R.A.; El-Ela, A.A.; Ali, E.S.; Mahmoud, K.; Lehtonen, M.; Darwish, M.M.F. Optimal Harmonic Mitigation in Distribution Systems with Inverter Based Distributed Generation. Appl. Sci. 2021, 11, 774. [CrossRef]

6. Ali, M.N.; Mahmoud, K.; Lehtonen, M.; Darwish, M.M.F. Promising MPPT Methods Combining Metaheuristic, Fuzzy-Logic and ANN Techniques for Grid-Connected Photovoltaic. Sensors 2021, 21, 1244. [CrossRef]

7. Sun, K.; Li, K.-J.; Wang, Z.-D.; Sun, H.; Wang, M.; Liu, Z.; Wang, M. Operation Modes and Combination Control for Urban Multivoltage-Level DC Grid. IEEE Trans. Power Deliv. 2017, 33, 360-370. [CrossRef]

8. Sun, K.; Qiu, W.; Yao, W.; You, S.; Yin, H.; Liu, Y. Frequency Injection based HVDC Attack-defense Control via Squeeze-Excitation Double CNN. IEEE Trans. Power Syst. 2021, 14, 1. [CrossRef]

9. Zhang, H.; Li, Y.; Gao, D.W.; Zhou, J. Distributed Optimal Energy Management for Energy Internet. IEEE Trans. Ind. Inform. 2017, 13, 3081-3097. [CrossRef]

10. GREE Photovoltaic Cabin-Bring Low Carbon Life in Toreality [EB/OL]. Available online: http://www.xinhuanet.com/tech/2018 -07/06/C_1123089628.htm (accessed on 6 July 2018).

11. Liang, L.; Guo, C.; Li, K.; Li, M. Economic scheduling of compressed natural gas main station considering critical peak pricing. Appl. Energy 2021, 292, 116937. [CrossRef]

12. Ravyts, S.; Vecchia, M.D.; Van den Broeck, G.; Hallemans, L.; Stul, K.; Driesen, J. Earth Fault Analysis and Safety Recommendations for BIPV Module-Level Converters in Low-voltage DC Microgrids. In Proceedings of the 2019 IEEE Third International Conference on DC Microgrids (ICDCM), Matuse, Japan, 20-23 May 2019; pp. 1-8.

13. Demidov, I.; Pinomaa, A.; Lana, A.; Pyrhönen, O. Fault detection and classification based on deep learning in LVDC off-grid system. In Proceedings of the 2020 22nd European Conference on Power Electronics and Applications (EPE'20 ECCE Europe), Lyon, France, 7-11 September 2020; pp. 1-10.

14. Ou, T.C. Ground fault current analysis with a direct building algorithm for microgrid distribution. Elect. Power Energy Syst. 2013, 53, 867-875. [CrossRef]

15. Chen, S.L. Stage fault test of a low voltage microgrid for development of protection scheme. Int. J. Smart Grid Clean Energy 2012, 1, 116-121. [CrossRef]

16. Carminati, M.; Ragaini, E.E. Considerations on DC side grounding configurations of LVDC microgrids. In Proceedings of the 2015 5th International Youth Conference on Energy (IYCE), Pisa, Italy, 27-30 May 2015; Institute of Electrical and Electronics Engineers (IEEE): Piscataway, NJ, USA, 2015; pp. 1-6.

17. Tang, L.; Ooi, B.-T. Managing zero sequence in voltage source converter. In Proceedings of the Conference Record of the 2002 IEEE Industry Applications Conference 37th IAS Annual Meeting, Pittsburgh, PA, USA, 13-18 October 2002; 2, pp. 795-802, Cat. No.02CH37344.

18. Carminati, M.; Ragaini, E.; Tironi, E. DC and AC ground fault analysis in LVDC microgrids with energy storage systems. In Proceedings of the 2015 IEEE 15th International Conference on Environment and Electrical Engineering (EEEIC), Rome, Italy, 10-13 June 2015; pp. 1047-1054.

19. Bendary, A.F.; Abdelaziz, A.Y.; Ismail, M.M.; Mahmoud, K.; Lehtonen, L.; Darwish, M.M.F. Proposed ANFIS Based Approach for Fault Tracking, Detection, Clearing and Rearrangement for Photovoltaic System. Sensors 2021, 21, 2269. [CrossRef] [PubMed]

20. Li, Z.; Lu, J.; Zhu, Y.; Jiang, W. Ground-fault characteristic analysis of grid-connected photovoltaic stations with neutral grounding resistance. Energies 2017, 10, 1910. [CrossRef] 
21. Mobarrez, M.; Fregosi, D.; Bhattacharya, S.; Bahmani, M.A. Grounding architectures for enabling ground fault ride-through capability in DC microgrids. In Proceedings of the 2017 IEEE Second International Conference on DC Microgrids (ICDCM), Nuremburg, Germany, 27-29 June 2017; Institute of Electrical and Electronics Engineers (IEEE): Piscataway, NJ, USA, 2017; pp. 81-87.

22. Paul, D. Phase-Ground Fault Current Analysis and Protection of a High-Resistance Grounded Power System. IEEE Trans. Ind. Appl. 2020, 56, 3306-3314. [CrossRef]

23. Naderi, S.B. Efficient fault ride-through scheme for three phase voltage source inverter-interfaced distributed generation using DC link adjustable resistive type fault current limiter. Renew. Energy 2016, 92, 484-498. [CrossRef]

24. Li, J.; Li, Y.; Xiong, L.; Jia, K.; Song, G. DC Fault Analysis and Transient Average Current Based Fault Detection for Radial MTDC System. IEEE Trans. Power Deliv. 2020, 35, 1310-1320. [CrossRef]

25. He, Z.; Hu, J.; Lin, L.; Chang, Y.; He, Z. Pole-to-ground Fault Analysis for HVDC Grid Based on Common-and Differential-mode Transformation. J. Mod. Power Syst. Clean Energy 2020, 8, 521-530. [CrossRef]

26. Emara, D.; Ezzat, M.; Abdelaziz, A.Y.; Mahmoud, K.; Lehtonen, M.; Darwish, M.M.F. Novel Control Strategy for Enhancing Microgrid Operation Connected to Photovoltaic Generation and Energy Storage Systems. Electronics 2021, 10, 1261. [CrossRef]

27. Abdel-Gawad, N.M.K.; El Dein, A.Z.; Magdy, M. Mitigation of induced voltages and AC corrosion effects on buried gas pipeline near to OHTL under normal and fault conditions. Electr. Power Syst. Res. 2015, 127, 297-306. [CrossRef]

28. Li, J.; Ouyang, Z. Quench Simulation in Cable-in-Conduit Conductor Using Runge-Kutta Discontinuous Galerkin Finite Element Method. IEEE Trans. Appl. Supercond. 2010, 20, 2098-2101. [CrossRef]

29. Schmitt, B.A.; Weiner, R. Equilibrium attractivity of Runge-Kutta methods. IMA J. Numer. Anal. 2001, 21, 327-348. [CrossRef]

30. Sangwongwanich, A.; Blaabjerg, F. Monte Carlo Simulation With Incremental Damage for Reliability Assessment of Power Electronics. IEEE Trans. Power Electron. 2021, 36, 7366-7371. [CrossRef] 